\title{
Referente a oral o bucal
}

\author{
With respect to oral or buccal
}

\author{
Lourdes Eriksen Persson*
}

\begin{abstract}
En la actualidad existe un conflicto con la forma de designar los elementos anatómicos del cuerpo humano ya que se utiliza la nomenclatura anterior, la que se fue elaborando con el nombre de cada autor que contribuyó en la forma de describir al cuerpo humano, la de los epónimos, la de los 50,000 nombres, la que nombra a la cavidad oral como cavidad bucal, a la língula mandibular como la espina de Spix, al conducto parotídeo como el conducto de Stenon porque así está descrito en la nómina francesa traducida al español, con la que muchas generaciones aprendieron anatomía y un alto porcentaje de libros especializados fueron traducidos.
\end{abstract}

Desde el inicio del siglo XX se utiliza una nómina anatómica simplificada, directa, de 5,000 nombres, sin epónimos, con una forma de orientarnos más puntual. De hecho, desde la óptica morfológica, se publica en el Congreso de Leningrado (1976) la primera lista de la Nomenclatura Histológica y Embriológica. ${ }^{1}$ Actualmente, con la necesidad de comunicarnos científicamente, es menester adoptar esta nómina anatómica simplificada y hacer el cambio.

Desde 1903 existe la Federación Internacional de Asociaciones de Anatomistas (IFAA), ${ }^{2}$ que se encarga de revisar cada cuatro años la Nómina Anatómica Internacional, creada en 1894, para simplificar la forma de designar las partes del cuerpo humano anatómicamente.

Entre los principios adoptados en la preparación de la Nómina Anatómica (1894) se rescatan:

1) Que bajo un número limitado de excepciones, cada elemento anatómico será designado con un solo término.

2) Cada término en la lista oficial deberá ir en latín; sin embargo, cada país tendrá la libertad de traducirlo a su propia lengua con fines didácticos.

3) Que los términos tengan primariamente valor descriptivo.

4) Los epónimos no deberán ser usados.

5) Los órganos estrechamente unidos topográficamente deben tener en la medida de lo posible nom- bres análogos (arteria femoral, vena femoral y nervio femoral).

Para el ámbito Odontológico, la Nomenclatura Anatómica (NA) divide a la Cavidad Oral (cavitas oris) en: vestíbulo oral (vestibulum oris) formado por: hendedura labial (rima oris), labios (labia oris), labio superior (labium superius), filtro (philtrum), tubérculo (tuberculum), labio inferior (labium inferius), comisura labial (comisura labiorum), ángulo oral (angulus oris), mejilla (bucca) y cuerpo adiposo de la mejilla (corpus adiposum bucae).

Y la cavidad oral propia (cavitas oris propia) formada por: túnica mucosa de la cavidad oral (tunica mucosa oris), glándulas orales (glandulae oris), dientes (dentes), lengua (lingua), músculos de la lengua (musculi linguae), fauces (fauces), músculos del velo del paladar (musculi palati et faucium), el paladar (palatum), dividido en paladar duro (palatum durum) y paladar blando o velo palatino (palatum molle), (velum palatinum), el rafé del paladar (raphe palati) y la faringe (pharynx).

No se pierde la palabra boca, ya que es el término usado coloquialmente, así como en inglés «mouth», en francés «bouche» o en alemán «mund».

Rápidamente, Rusia, Estados Unidos de Norteamérica, Italia y los países de habla alemana la adoptaron, en Inglaterra se difundió con lentitud, en cambio Francia se resistió a usarla, y ocurre que de ahí derivan los términos anatómicos que durante decenios se usaron en todo el mundo.

En nuestro país, derivado de la nómina anterior, la de los epónimos, el texto del Doctor Fernando Quiroz (quien tradujo del francés el libro de anatomía Testut-

\footnotetext{
* Profesora de Anatomía Humana, División de Estudios Profesionales, Facultad de Odontología, UNAM.
}

Este artículo puede ser consultado en versión completa en http://www.medigraphic.com/facultadodontologiaunam 
Latarjet) era el más importante y respetado, con el que muchos profesionistas de la salud aprendieron anatomía humana, era utilizado el término bucal al describir los elementos relacionados con la hendedura labial y que divide a la boca en vestíbulo y cavidad oral propiamente dicha, ya que así fue descrita en francés, y así permaneció desde los años cuarenta. Hasta la fecha, el libro del Dr. Quiroz, jamás fue actualizado y con esos conocimientos fueron traducidos los libros consecuentes.

Actualmente, ya no es el texto del Doctor Quiroz el que rige la enseñanza de la Anatomía, sino que son muchos los autores que, desde los años sesenta, han podido penetrar el mercado mexicano, y nos han traído los cambios en la forma de describir la anatomía humana haciéndola más sencilla, más directa, sin tantos nombres para un solo elemento anatómico, con un lenguaje muy claro y con las directrices adecuadas; estos libros nos llegan ya no de Francia, sino de Estados Unidos, de Inglaterra, de Canadá y en un tiempo hasta de Rusia. El serio problema de estos libros eran las traducciones, las cuales eran hechas por profesionistas especializados que no conocían la Nomenclatura Anatómica Parisina (PNA). De tal forma que los libros comenzaron a tener una mezcla extraña de términos de las dos nóminas, como le ocurrió al Voss Herlinger de los años setenta. Como consecuencia, para los traductores los términos oral y bucal eran indistintos y siguen siendo así, no hay una separación anatómica definida por lo que todavía nos encontramos en transición.

Otro evento es que han sido traducidas correctamente dos o tres ediciones y la siguiente está traducida con la nómina anterior debido al cambio de traductor. Otro suceso es el ocurrido al libro de La Tarjet-Ruiz Liard, en el que la segunda y la tercera ediciones fueron elaboradas con la NA, desafortunadamente mueren los autores, y en la cuarta edición se respetaron sus nombres, como autores, pero elaborada por otras personas regresa a la nómina anterior haciendo a un lado años de trabajo.

Actualmente, la mayoría de los países utilizan la terminología internacional para conferir a la enseñanza de las ciencias morfológicas la facilidad de aprendizaje, en contraposición al esfuerzo memorístico de los tiempos de la tradicional terminología francesa con epónimos.
La anatomía es parte de los fundamentos de la educación médica, y ha sido una constante en la enseñanza desde el Renacimiento. El formato y la cantidad de información que se ha enseñado ha evolucionado y cambiado a la par de las demandas de la profesión.

Hoy, la globalización nos obliga a tener formas de comunicación especializadas y específicas que permitan un entendimiento sencillo y claro de la nómina. Es parte de toda profesión el utilizar el lenguaje científico común que permita la integración internacional.

Finalmente, es necesario traducir los términos de latín al español, si queremos información actualizada. La Facultad de Odontología de la Universidad Nacional Autónoma de México es líder en conocimiento y en educación continua. Si pretendemos salir y exponer nuestros trabajos, o escuchar a otros investigadores, y si somos docentes, tenemos la responsabilidad de estar a la vanguardia y conocer estos cambios para que también nuestros alumnos entiendan el lenguaje científico odontológico y así tener acceso a la información; debemos sumarnos al resto de los países que ya utilizan de manera cotidiana la terminología actual; incluso los franceses ya adoptaron esta nomenclatura anatómica internacional desde $1976 .{ }^{3}$

En conclusión, ¿es oral o bucal?, definitivamente es ORAL, en la nomenclatura anatómica actual, la OMS, la OPS, hablan de la salud oral; bucal quedó en la pared del vestíbulo. Así como el mundo tuvo la necesidad de unificar la forma de estudiar el cuerpo humano, con un lenguaje científico, así nosotros debemos sumarnos a esta unificación para comunicarnos con el mismo lenguaje en el ámbito Odontológico y con el mundo.

\section{REFERENCIAS}

1. Gardner, Gray, O'Rahilly. Anatomy. A regional study of human structure. $4^{\text {rd. }}$ ed. W.B. Saunders Company, 1975.

2. DiDio LJ. Historical aspects of the International Federation of Associations of Anatomists. Anat Anz. 1990; 170 (2): 133-6. PMID 2185674.

3. Nguyen Huu, Vallée B, Person H. Nouveaux Dossiers D'Anatomie PCEM. Heures de France. 16, rue des Vignettes, 78770 Thoiry. 1994.

Dirección para correspondencia:

Lourdes Eriksen Persson

E-mail: lourdeseriksen@yahoo.com 